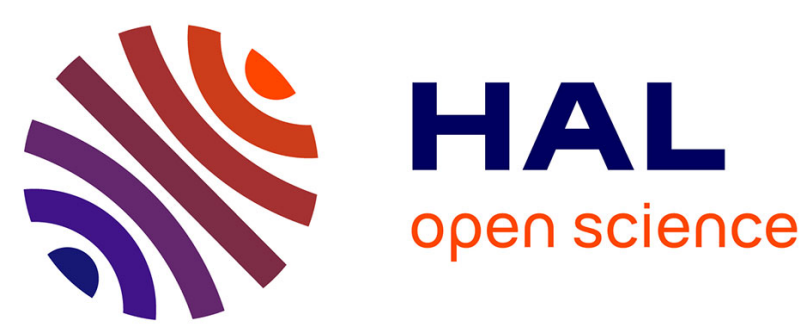

\title{
Compact and High Performance Wind actuated venturi triboelectric energy harvester
}

Aravind Narain Ravichandran, Cyril Calmes, Julien Serres, Marc Ramuz, Sylvain Blayac

\section{> To cite this version:}

Aravind Narain Ravichandran, Cyril Calmes, Julien Serres, Marc Ramuz, Sylvain Blayac. Compact and High Performance Wind actuated venturi triboelectric energy harvester. Nano Energy, 2019, 62, pp.449-457. 10.1016/j.nanoen.2019.05.053 . hal-02157346

\section{HAL Id: hal-02157346 \\ https://hal-amu.archives-ouvertes.fr/hal-02157346}

Submitted on 16 Jun 2019

HAL is a multi-disciplinary open access archive for the deposit and dissemination of scientific research documents, whether they are published or not. The documents may come from teaching and research institutions in France or abroad, or from public or private research centers.
L'archive ouverte pluridisciplinaire HAL, est destinée au dépôt et à la diffusion de documents scientifiques de niveau recherche, publiés ou non, émanant des établissements d'enseignement et de recherche français ou étrangers, des laboratoires publics ou privés. 
archives-ouvertes

\title{
Compact and High Performance Wind actuated venturi triboelectric energy harvester
}

\author{
Aravind Narain Ravichandran, Narain Ravichandran, Cyril Calmes, Julien
}

Serres, Marc Ramuz, Sylvain Blayac

\section{To cite this version:}

Aravind Narain Ravichandran, Narain Ravichandran, Cyril Calmes, Julien Serres, Marc Ramuz, et al.. Compact and High Performance Wind actuated venturi triboelectric energy harvester. Nano Energy, Elsevier, 2019, 62, pp.449-457. 10.1016/j.nanoen.2019.05.053 . hal-02157346

\section{HAL Id: hal-02157346 \\ https://hal-amu.archives-ouvertes.fr/hal-02157346}

Submitted on 16 Jun 2019

HAL is a multi-disciplinary open access archive for the deposit and dissemination of scientific research documents, whether they are published or not. The documents may come from teaching and research institutions in France or abroad, or from public or private research centers.
L'archive ouverte pluridisciplinaire HAL, est destinée au dépôt et à la diffusion de documents scientifiques de niveau recherche, publiés ou non, émanant des établissements d'enseignement et de recherche français ou étrangers, des laboratoires publics ou privés. 


\title{
Compact and High Performance Wind actuated venturi triboelectric energy harvester
}

Aravind Narain Ravichandran ${ }^{a}$, Cyril Calmes ${ }^{a}$, Julien R Serres ${ }^{b}$, Marc Ramuz ${ }^{a}$, Sylvain Blayac ${ }^{a}$

${ }^{a}$ Mines Saint-Etienne, Center of Microelectronics in Provence, Department of Flexible Electronics, France

${ }^{\mathrm{b}}$ Aix Marseille Univ, CNRS, ISM, Marseille, France

\begin{abstract}
The growing need for alternative sources to power Internet of Things and autonomous devices has led to many energy harvesting solutions from ambient energy sources. Use of batteries requires complementary energy source for extending the lifetime of the device. In recent times, triboelectric nanogenerators have gained significant attention in charging applications through ambient energy harvesting field due to their simplicity, efficiency and adaptability to many device configurations in nature. It is deemed to sustainably address power for autonomous smart applications in various environmental conditions. In this work, a state-of-the-art triboelectric nanogenerator based on wind actuated venturi design system is demonstrated in sync with the smart system evolution for powering various sensor nodal network. Using natural wind, the 3D printed wind actuated venturi triboelectric energy harvester converts ambient mechanical energy into electricity. This simple and compact device produces an optimum average power of $1.5 \mathrm{~mW}$ and produces a maximum output power density of $2850 \mathrm{~mW} \cdot \mathrm{m}^{-2}$ (peak power output of $4.5 \mathrm{~mW}$ ), which is much higher than the existing reports that use larger surface area at higher wind velocity. Extensive material testing and future implementation in an array of applications aids for environment friendly energy production and increase the role of triboelectric nanogenerator in autonomous applications.
\end{abstract}

Keywords: Triboelectric Nanogenerator; Energy harvesting; Power density; Wind energy; Triboelectric materials; Contact electrification. 


\section{Introduction}

With the rapid development of autonomous devices and sensors for Internet of Things (IoTs) applications, batteries cannot meet the sustainable energy requirement due to their limited lifetime, size and maintenance. Energy harvesting often refers to photovoltaics for such applications. However, sun illumination is sometimes scattered or restricted to locations. As an alternative, mechanical energy harvesting could be intelligently associated to diversify the energy sources.

Other ambient energies such as wind energy have been considered as an attractive energy source due to their copious, ubiquity, and feasibility in nature[1]. The wind energy turbines based on electromagnetic transduction seem to be a viable solution for our ever-demanding energy problems. Unlike the batteries, they are a clean energy source and thus do not pollute the environment. The need for compact and long life energy sources can be achieved by the development of energy harvesting techniques that are either used as a primary energy source or work in concurrence with batteries to increase the power generation with less environmental degradation and long term operation.

Advancement in microelectronics has led to the miniaturization of sensors and devices, for instance, micro-controllers with reduced power consumption[2][3] as low as $5 \mu \mathrm{W}$ with high efficiency. Triboelectric nanogenerator(TENG) have been conceived as a promising technology by harvesting mechanical energy for powering such low-power electronics[4] with a potential power density of 500 W. $\mathrm{m}^{-2}$ and an energy conversion efficiency of more than $70 \%[5]$. The triboelectric phenomenon as an energy harvesting technique was first reported by Prof. Wang in 2012[6]. The TENGs generate electricity converting the mechanical motions through the coupling of triboelectrification and electrostatic induction[7].

With the development of the autonomous sensor systems requiring the availability of compact and efficient power sources, the wind turbines are either expensive, bulky, inefficient or not suited for these microscale applications[8][9]. Researchers have investigated on ambient wind energy harvesting based on various harvesting techniques including triboelectric transduction[10][11][12][13]. With the recent reports on ambient energy harvesting by triboelectricity gaining significant attention mainly due its simple fabrication, low cost and wide array of applications[14][15][16][17], challenges remain 
mainly on the device size, output electrical performance, efficiency and implementation in real life environment.

Environmental factors such as humidity, temperature and pressure can alter the triboelectric material properties and thus the performance of the triboelectric nanogenerator[18][19][20]. Since the triboelectric nanogenerator is deployed to stay in the environment for ambient energy harvesting for extended period of time, the long-term stability of its material property must be considered suitable for long-term operations and its easy deployment aids for environment friendly energy production for autonomous applications.

Periodic contact-separation cycles between different surfaces with oppositely polarized triboelectric charges can change the induced potential difference across two electrodes, thus driving the alternating flow of electrons through an external load[21][22]. Previous reports emphasize mostly on the application perspectives[23][24][25], however more work has to be achieved in order to improve the device output performance[26][27][28][29] by using application suited materials. Very few reports[30][31] acknowledge the average or RMS (Root Mean Square) output performance which is very important to access the effective available average output power. Although peak power outputs provide maximum harvested power, the key parameter is the RMS power which indicates the average power output at any condition to convert mechanical wind energy to electrical energy.

The present work is focused on the development of a Wind Actuated Triboelectric Nanogenerator (WATENG) based on flutter-driven structure that resolves the existing concerns, namely, the size, reliability and output electric performance. The wind is channelized through a venturi design system inducing periodic vibration of a flag film. Figure 1 (a) shows the important sections of a venturi system consisting mainly of the inlet (convergent), outlet (divergent) and throat. When the ambient air passes through the venturi system, a low pressure exists in the throat region forcing the flag film to flutter at high frequencies between the electrodes. This flag fluttering is translated into a faster charge transfer efficiency by displacing the charge between the electrodes. This charge movement induces a potential variation at the electrodes and an enhanced triboelectrification process. With Polycarbonate (PC) as the flag film displacing at $5 \mathrm{~m} \cdot \mathrm{s}^{-1}$ between Polytetrafluoroethylene (PTFE) - Copper (Cu) electrodes, the 
device delivers an output voltage (Vo) of $150 \mathrm{~V}$ and short-circuit current (Isc) of $16 \mu \mathrm{A}$ outperforming existing reports[24][26][32][33][34] with a $1.5 \mathrm{~mW}$ RMS power and $4.5 \mathrm{~mW}$ peak power outputs. The optimized output performance of the WATENG has been accomplished by systematically evaluating the effects of the wind speeds, material screening and structural parameters. The WATENG system was used to glow 40 series connected commercial LEDs instantaneously with a very bright illumination without any rectification and charge a $100 \mu \mathrm{F}$ capacitor to $5 \mathrm{~V}$ within 20 secs validating its potential to power for small scale electronics. Device sizing not only enhances the output performance but also addresses to various environmental sensor applications. To demonstrate the real-world application, the WATENG system was employed to charge a $1 \mathrm{mF}$ super capacitor to $15 \mathrm{~V}$ in less than 12 minutes to harvest the ambient wind by mounting the WATENG on the car roof top. With an efficient charging of a storage device, we believe the WATENG is adaptable not only for powering small electronics but can contribute to ubiquitous large-scale energy harvesting.

\section{Design and fabrication of WATENG}

The wind flows into the WATENG system with inner dimensions of $2.1 \mathrm{~cm}(\mathrm{~W}) \times 2.1 \mathrm{~cm}(\mathrm{H})$ inducing the periodic vibrations of the flag film in the venturi design structure, which can drive the TENG. Figure 1(b) illustrates the schematic diagram and Figure $1(\mathrm{c})$ and $1(\mathrm{~d})$ of the fabricated WATENG, which consists of a venturi system design with PC as the flexible flag and PTFE - $\mathrm{Cu}$ as the side electrodes. A PC film flag $(6.8 \mathrm{~cm} \times 1.9 \mathrm{~cm})$ with a thickness $125 \mu \mathrm{m}$ (SABIC, Inc.) was used as a triboelectric material in the TENG. Since the flag film flutters at various wind speeds, PC is a very good candidate owing to its easy availability, good flexibility and a very high impact strength with a tensile strength ( $\sigma \mathrm{t})$ of 55$75 \mathrm{MPa}[35]$. They are both eco-friendly and has been proven to show excellent stability at temperatures as high as $140^{\circ} \mathrm{C}[19]$. A $100 \mu \mathrm{m}$ thin PTFE film (Goodfellow Ltd.) was chosen for its high electron affinity and high dielectric strength[36] with dimensions $4.5 \mathrm{~cm}(\mathrm{~L}) \times 2.1 \mathrm{~cm}(\mathrm{~W})$ wedged to the adhesive copper film serving as the two electrodes. The venturi structures were 3D printed (Ultimaker 3) for precise structural control and enclosed on all sides by microscopic glass slides $(7.5 \mathrm{~cm} \times 2.1 \mathrm{~cm})$. To create a uniform wind flow into the venturi inlet channel, custom made wind tunnel was devised. The PC flag film was fixed to the center position using the holders at the mouth of the venturi system. 
The venturi design creates a depression at the throat that varies the flag fluttering characteristic through the system. The venturi effect[37] is employed to concentrate the air flow in the outlet section (divergent), which increases the velocity of fluttering motion and a low-pressure region (throat) is created behind outlet and inlet sections with an optimum gap spacing. With increase in wind velocity, the throat pressure decreases, increasing the flag fluttering frequency. The relationship between the velocity and pressure can be expressed from Bernoulli equation[38] as

$$
p 1-p 2=\frac{1}{2} \rho\left(v 2^{2}-v 1^{2}\right)
$$

where $\mathrm{p} 1, \mathrm{p} 2$ are the inlet and outlet pressure, $\rho$ is the density of air and $\mathrm{v} 1, \mathrm{v} 2$ are the wind velocity at the converging and diverging sections. The $\mathrm{v} 1$ is the slower wind velocity at the converging section and $v 2$ is the faster wind velocity at the diverging section. The above equation describes that, in the event of a pressure drop, the velocity increases and vice versa. To avoid the undue aerodynamic drag, the venturi system has an entry cone of 30 degrees and an exit cone of 5 degrees[39].

Initially, the PC flag film is at rest in middle position (Figure $1(\mathrm{e}) \mathrm{I}$ ), related to its orientation and material stiffness. The film begins to move associated to the wind flow direction thanks to viscous frictions. With increasing velocity, the film starts to collide/oscillate/flutter periodically (Figure 1(e) II). Therefore, the kinetic energy from the ambient source is converted into mechanical energy of oscillating motion, which can be converted into electrical energy. The incoming wind speed in the experimental section ranges from 0 to $10 \mathrm{~m} \cdot \mathrm{s}^{-1}$, which includes the global average wind speed of 3.28 $\mathrm{m} \cdot \mathrm{s}^{-1}[40]$.

\section{Measurement setup}

For the measurement of WATENG, the wind was propelled using a commercial air gun connected to a compressed air supply controlled by a pressure regulator with regulated $30 \%$ relative humidity $(\mathrm{RH})$ conditions. A commercial anemometer from Voltcraft PL-135 was engaged in measuring the wind velocity. The output electric parameters of WATENG were measured using a Keithley 2636 sourcemeter and LeCroy waveRunner 6100A oscilloscope with a $10 \mathrm{M} \Omega$ impedance by a LabVIEW program for real time data acquisition. The impedance matching was performed using a wide-range resistance ladder configuration with external load ranging from $1 \mathrm{k} \Omega$ to $376 \mathrm{M} \Omega$. 
a

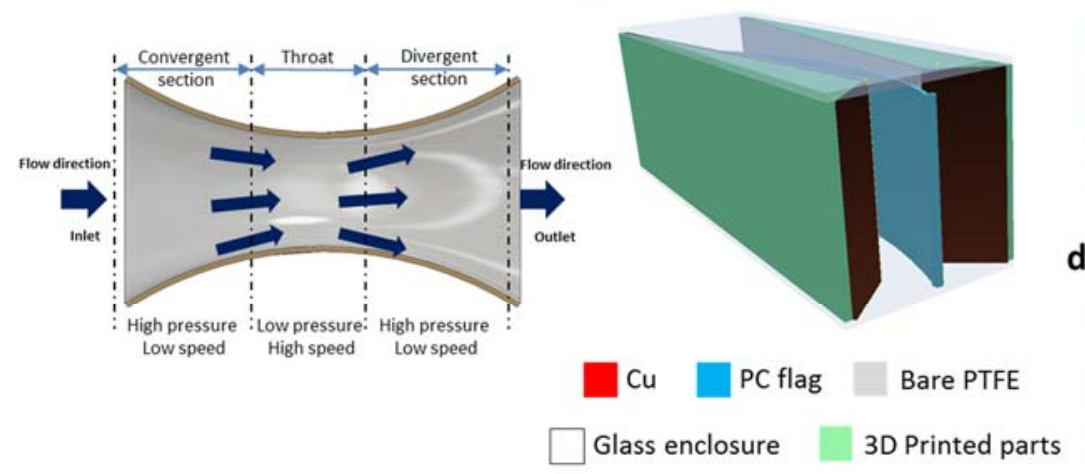

e

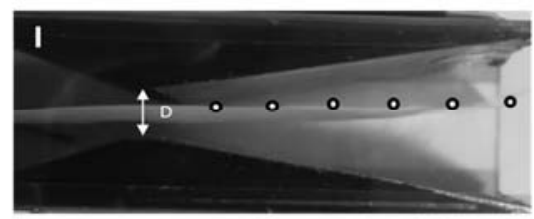

II

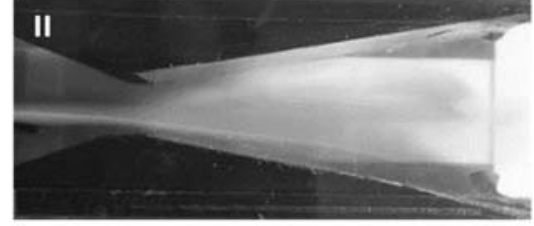

f

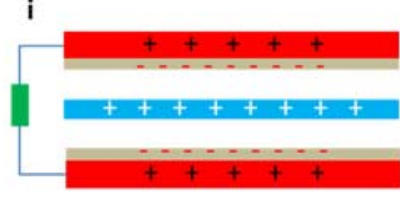

iv

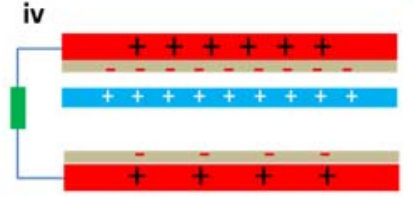

C 3 D Printed spacers Electrodes

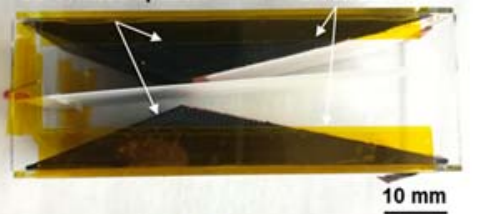

$10 \mathrm{~mm}$

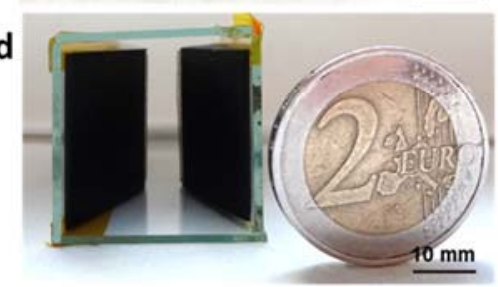

ii

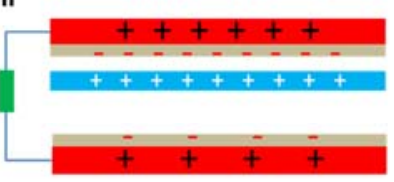

iii

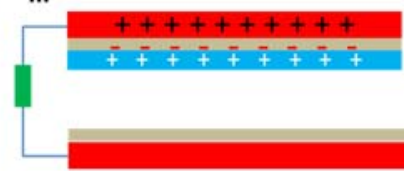

Figure 1. a) Venturi system consisting the inlet (convergent), outlet (divergent) and throat sections. b) $3 D$ schematic of the WATENG. c), d) Photographs of the WATENG consisting of venturi system design with PC as the flexible flag and PTFE - CU as the side electrodes. e) PC flag orientation positions: (I) Initial position, (II) under oscillation. $f$ ) The working principle of the WATENG. (i) Flag at its initial position between the electrodes. (ii) The flag displaces towards one of the electrodes driving the electrons from the bottom to the top electrode. (iii) On contact the triboelectric charges (equal and opposite) are created on the PTFE and PC flag. (iv) Charges flow in reverse direction relative to the flag position.

\section{TENG operation principle}

The working mechanism of the WATENG consists of different processes as illustrated in Figure 1(f).

Intermittent contact separation between PTFE - $\mathrm{Cu}$ electrodes and PC flag film with different triboelectric polarities drive charges back and forth in short-circuit conditions due to the coupling of triboelectrification and electrostatic induction processes[7]. The triboelectrification process occurs at the mechanical contact between the flag and the electrodes. The flag is thus carrying a charge Qe and the movement of this charge either induces a voltage variation in open circuit conditions or transfers charges in the form of current in short circuit conditions. The amount of electric charge Qe created on the moving flag remains a constant and is linearly related to the change in electric potential $V$ with capacitance $\mathrm{C}$ at a certain wind velocity. This relation can be seen as

$$
Q_{e}=C . V
$$


The capacitance $C_{\text {total }}$ between the electrodes determines the amount of charge the PC flag can hold. The capacitance depends on the gap distance $2 \mathrm{w}$ between the electrodes and the contact surface area of the electrodes $A$.

$$
C_{\text {total }}=\frac{\in A}{2 w}
$$

where $\in$ is the vacuum dielectric constant.

When the distance between the electrodes decreases, the capacitance increases, resulting in a lower output voltage. If the two electrodes are unconnected to external load, there exists a potential difference between the electrodes creating an open-circuit voltage Voc. Assuming the gap spacing $w$ uniform throughout the design structure, a theoretical model is conceptualized treating the electrodes and the moving flag as a parallel plate capacitor model without considering the edge effect[41]. The detailed analytical derivation is presented in the Supplementary Information S3. The amplitude of open circuit voltage can be determined by

$$
V_{\text {peak-to-peak }}=\frac{\left|Q_{e}\right|}{\in A} \cdot 2 w
$$

The charge transfer mechanism between the contacting materials depends on their triboelectric series position and electron affinities[42]. At first (I), there exists no electric potential difference between the electrodes. As the wind enters the system, the PC flag displaces (II) from its initial position towards one of the electrodes due to the pressure depression created in the venturi system channel. When the flag contacts the PTFE film (III), the negative charges are created on the PTFE due to triboelectrification, leaving the PC positively charged and driving the electron flow from the bottom to the top electrode. A similar trend exists when the flag displaces to the counter electrode (IV). This continuous fluttering of the flag on the electrodes results in a cyclic alternating current $(A C)$ output signal relative to the wind speed. The fluttering movement of the flag the electrodes results in the creation of charges on the PTFE surface. The rate of transfer of charges primarily depends on the wind velocity and the output short current Isc with a wind velocity $v$ given by

$$
I s c=\left|Q_{e}\right| \cdot \frac{v}{2 w}
$$

The wind velocity $v$ can be expressed as a function of the fluttering frequency $f$ and is given by 


$$
f=\frac{v}{w}
$$

A continuous alternating current is produced due to the periodic charge transfer between the top and the bottom electrode material relative to the flag fluttering movement. With increase in flag fluttering frequency, the short circuit current Isc increases due to the faster rate of charge transfer between the electrodes. The relationship between the short-circuit current $I s c$ and the fluttering frequency $f$ can be deduced to

$$
I_{s c}=\left|Q_{e}\right| \cdot \frac{f}{2}
$$

Therefore, the short circuit current is proportional to fluttering frequency which increases with increase in the wind velocity.

\section{Wind flag behavior}

The oscillation produced by the PC flag is non-uniform at high wind speeds. To better understand the WATENGs flag behavior between the electrodes and the flag, a high-speed camera (Phantom Miro M110) at a frame rate of 1600 frames per second at full $1280 \times 800$ pixels resolution was employed. The camera was modulated by a control system which adjusts the illumination and the angle of vision for synchronized high quality images. The synchronous measurement control system is setup using a trigger controlling both the oscilloscope and the camera to correlate the output electric signals to the flag movements. The high-speed camera videos are available in supplementary information Movie S1. The fragmentation of images into six stages is proposed as seen in Figure 2(a) (I-VI) to demonstrate the contact separation mechanism between the electrodes and the flag materials. Figure 2 (b) shows the electric output signal of the contact separation mechanism of the WATENG into the electrode channel generated for 1.317 seconds. In order to understand the wind flag behavior, one complete oscillating cycle of contact separation with an output voltage between $\pm 150 \mathrm{~V}$ was measured. When the wind enters the venturi channel system, the flag begins to move from its initial position (TO) by oscillating towards the electrode with a high mechanical force $(\mathrm{T} 0+1 \mathrm{~ms})$. The contact area increases as the wind passes through the WATENG system resulting in triboelectrification (creation of equal and opposite charges) on the flag and the electrode (T0+2ms). The PTFE gaining negative charges on its surface while the PC flag gaining positive charges. The flag carries a fixed charge displacing it to the counter electrode 
(T0+3ms) resulting in the movement of mobile charges in the $\mathrm{Cu}$ electrode and inducing a current flow in positive direction relative to the flag fluttering displacement. The parasitic in the output signals exists due to the fast flag fluttering frequency creating a non-uniform contact with the electrodes (T0+4ms) as seen on Figure 2(a). The wind velocity transforms the mechanical energy of flag oscillating motion, which can be converted into electrical energy. Due to the flag fluttering at high frequencies, the flag propagates along the wind flow direction with increase in contact area ( $\mathrm{T0}+5 \mathrm{~ms})$ translating to a movement of the mobile charges in Cu electrode inducing current in opposite direction, resulting in AC current output signals in the external circuit. The resultant output voltage is the reflection of measured current output. The output current is governed primarily by the wind velocity, attributed to a faster rate of charge transfer due to higher flag fluttering frequency and higher contact surface area with the electrodes. This periodic displacement of the flag cycle continues until the wind flow is propagated in the wind channel. 
a
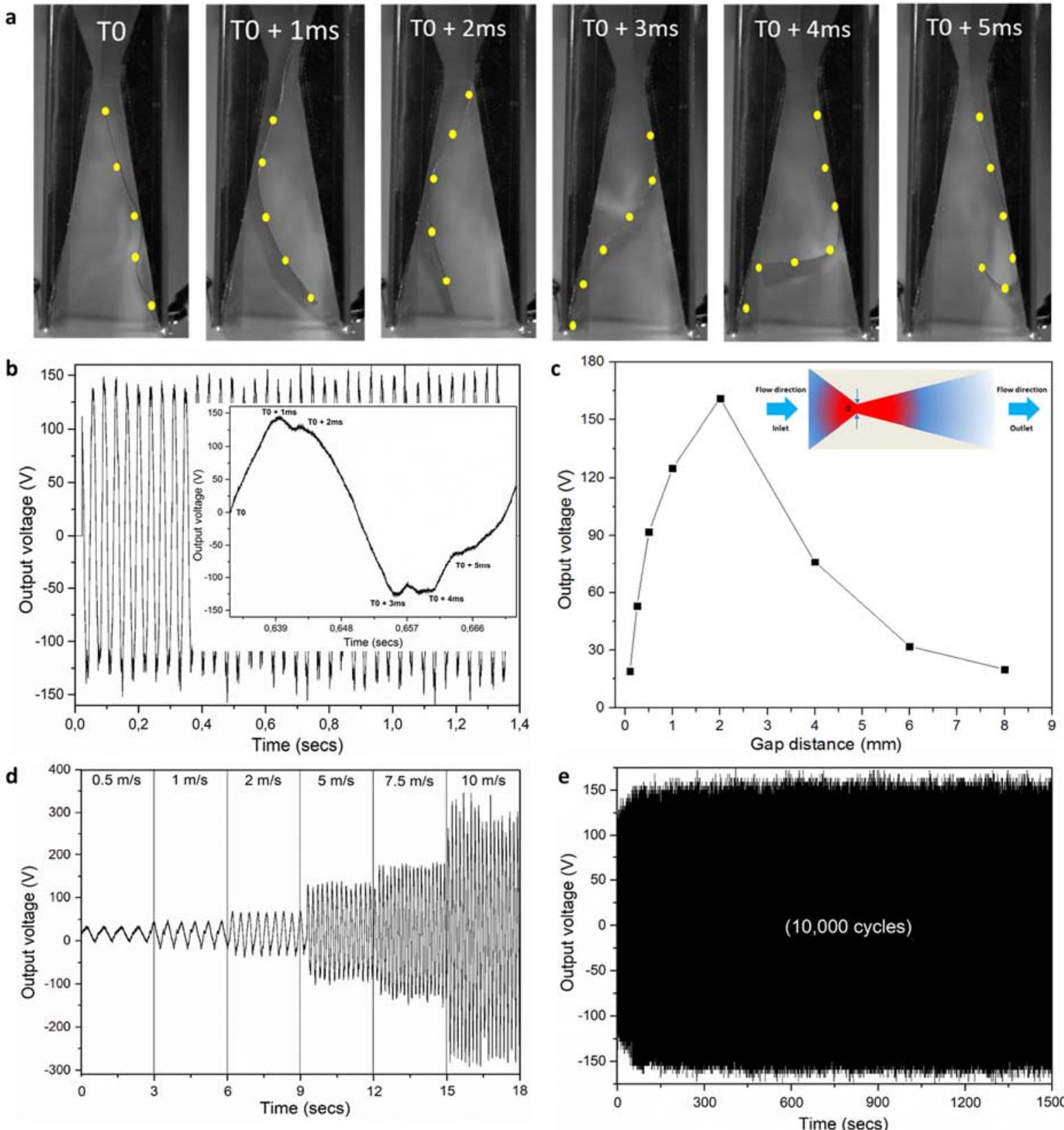

Figure 2. Relation between the voltage profile and wing flag behavior. a) Serial images of wind flag behavior of flexible PC flag captured using high speed motion camera (TO $\rightarrow$ TO+5ms). b) Voltage output profile of WATENG at $5 \mathrm{~m} \cdot \mathrm{s}^{-1}$, inset, a single voltage output cycle. c) Output potential induced by WATENG at different gap spacing. An optimum gap spacing of $2 \mathrm{~mm}$ is chosen for a better charge transfer process. d) Performance of output voltage as a function of wind speed. The output voltage drifts from $20 \mathrm{~V}$ at $0.5 \mathrm{~m} . \mathrm{s}^{-1}$ to $350 \mathrm{~V}$ at $10 \mathrm{~m} . \mathrm{s}^{-1}$. Increasing the wind speed increases the flag oscillation relating to a faster charge transfer mechanism. e) PC flag reliability with respect to a wind speed of $5 \mathrm{~m} \cdot \mathrm{s}^{-1}$, a stable $150 \mathrm{~V}$ output voltage is reached without any degradation in performance.

\section{Device output performance}

With an increase in the wind velocity, there exists a consequential drop in pressure at the throat resulting in a faster fluttering frequency. With the wind air density forced to pass through the reduced throat gap spacing, the minimum pressure occurs at the throat region between the inlet and outlet sections. Moreover, given an inlet pressure, an increase of pressure difference between the inlet and outlet of venturi tube makes the throat pressure drop further[43]. 
The gap spacing $d$ is selected based on the fact that higher fluttering frequency leads to a faster charge transfer between the electrodes, thus increasing the output electric signals. Figure 2(c) validates the output voltage with the various gap spacing tested at $5 \mathrm{~m} . \mathrm{s}-1$. When the gap spacing is $8 \mathrm{~mm}$ (wider), higher pressure at the throat leads to slower flag fluttering frequency with decrease in charge transfer while a $0.2 \mathrm{~mm}$ (narrow) gap spacing results in a faster fluttering frequency with faster charge transfer. The narrow gap spacing may be advantageous in terms of smaller device volume, higher contact area and increased device robustness but also for better performance of charge transfer efficiency. Gap spacing lower than $2 \mathrm{~mm}$ resulted lower output due to stagnation of the flag fluttering owing to high pressure created at the throat section. An optimum gap spacing of $2 \mathrm{~mm}$ is chosen for a better triboelectrification and device stability.

To determine the optimum electrical output performances as a function of wind speed, the measurements were performed with speeds varying from $0.5 \mathrm{~m} \cdot \mathrm{s}^{-1}$ to $10 \mathrm{~m} \cdot \mathrm{s}^{-1}$. Figure $2(\mathrm{~d})$ shows the voltage output comparison as a function of wind speed, the output voltage drifts from $20 \mathrm{~V}$ at $0.5 \mathrm{~m} . \mathrm{s}^{-}$ ${ }^{1}$ to $350 \mathrm{~V}$ at $10 \mathrm{~m} \cdot \mathrm{s}^{-1}$. The average natural wind does not exceed $10 \mathrm{~m} \cdot \mathrm{s}^{-1}$. The output voltage depends on the contact area and the fluttering frequency, both of which increase with higher wind speeds. It is explained by the fact that increasing the wind speed increases the flag oscillation relating to a faster charge transfer mechanism. The detailed analytical derivation is presented in the Supplementary Information S3. Furthermore, higher speed generates higher flux and higher current leading to higher charge transfer and voltage rates. According to the theory of freestanding triboelectric layer based nanogenerator[44], WATENG could be considered as a capacitor with a constant transferred charge through both electrodes. The output voltage is directly the translation of the wind velocity and the flag fluttering frequency which results in a varying output current owing to a faster charge transfer between the electrodes. As the wind speed increases, the flag oscillation becomes irregular and chaotic owing to uneven contact area and output performance resulting in saturation of the charge density. To demonstrate the WATENGs stability for long term continuous operation to obtain the maximum performance, the output voltage was measured for more than 1000 seconds which corresponds to approximately 10000 cycles presented in Figure 2(e). The PC flag transfers the charges between the 
electrodes at a constant $5 \mathrm{~m} \cdot \mathrm{s}^{-1}$ wind speed evidencing no decline is observed after a long-term continuous operation.

\section{Triboelectric material pairs}

Triboelectric series

To efficiently convert the mechanical wind energy to electrical energy by TENG, the material selection plays a key role for a better triboelectrification process. The material tendency to donate or receive electrons is based on triboelectric series as presented in Figure 3(a)[45]. When two different materials come in contact (pressed or rubbed), an electron transfer occurs between the two materials related to the difference in electronegativity. The material that gain electrons tends to have stronger affinity for negative charge of the two materials leading to a negative charge on the surface after the material separation. The material losing electrons will have the equal and opposite (positive) amount of charges. Higher up the list gives up electron and lower down the list receives electron. Further away two materials are separated apart from each other in the series, the greater the charge transferred. To achieve higher performance, materials further away from each other in the series are chosen due to their different ability to attract electrons.

The selection of two materials from the triboelectric series which are significantly separated from each other is highly important for TENGs, to induce a large charge transfer between the materials. Measuring the RMS voltage (Vrms) or the effective voltage helps in determining the best performing flag-electrode pair. Electrode materials such as $\mathrm{Cu}$, PTFE - $\mathrm{Cu}$ and Indium Tin Oxide (ITO) are tested against flag materials Polyimide (PI), Polyethylene terephthalate (PET) and PC. For improved output comparison, the PTFE - Cu electrode is tested with PTFE flag material proving its lowest RMS value. Figure 3(b) shows the output RMS voltage of the electrode flag pairs. The Vrms increased from $\sim 4 \mathrm{~V}$ in the device with ITO/PET:PI pair up to $\sim 100 \mathrm{~V}$ in the device with PTFE - Cu:PC electrode flag pair; validating the PTFE - Cu electrode as the best electrode material. Due to presence of fluorine atoms, the PTFE tends to be more negatively charged owing to its faster electron creation and transfer and also due to its position in the triboelectric series, standing as the most negative triboelectric material. 
a

Most positively charged

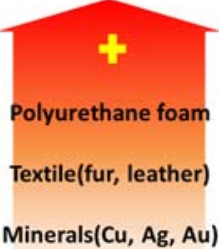

Synthetic(Rubber, polyester)

Polymer(Polycarbonate, PET, PVC)

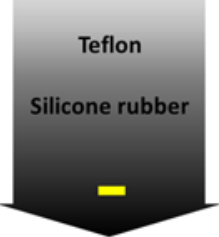

Most negatively charged

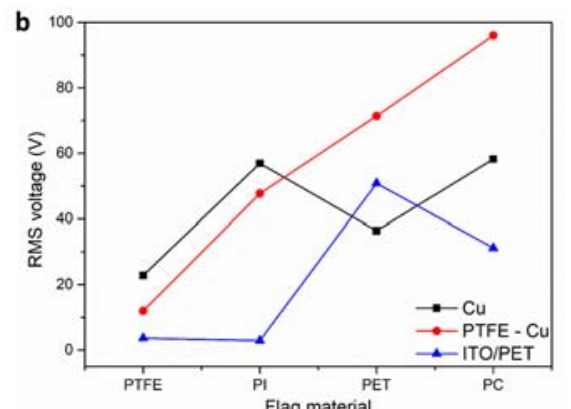

d

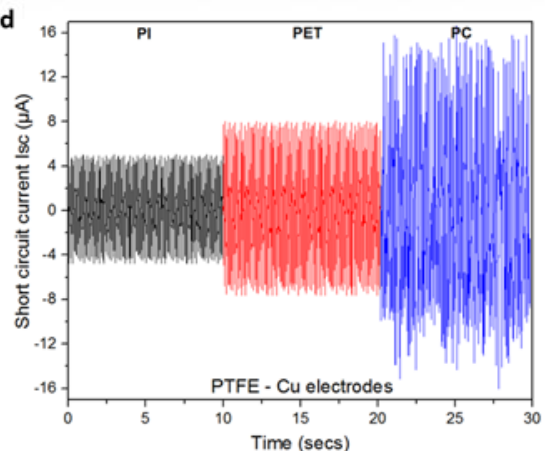

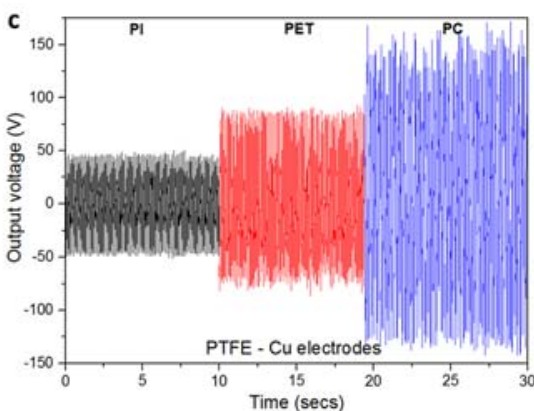

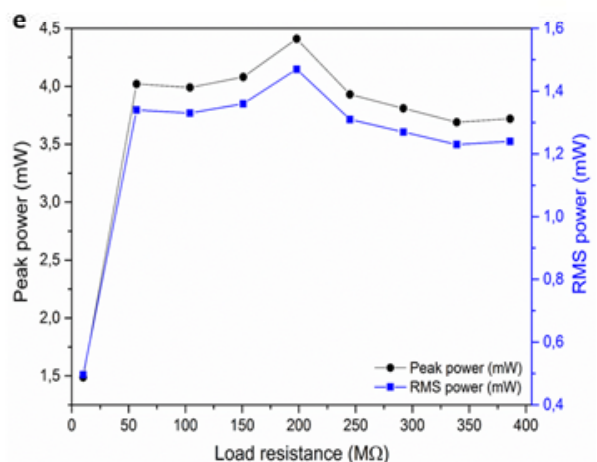

Figure 3. Output performance of WATENG system. a) Materials arranged in triboelectric series reproduced from [45]. b) The generated RMS voltage (Vrms) increased from $\sim 4 \mathrm{~V}$ in the device with ITO/PET: PI pair up to $100 \mathrm{~V}$ in the device with PTFE - CU: PC electrode flag pair. c) Output voltage for different materials with PTFE - Cu electrodes. The output voltage increases from $80 \mathrm{~V}$ with PET to $150 \mathrm{~V}$ in the device with flexible PC flag. Note: Identical experimental conditions were a used in all TENGs. d) Comparative short-circuit current (ISC) of the TENG with PTFE - Cu electrode with PI, PET and PC flag. e) Dependence of output power on the external load resistance $1 \mathrm{k} \Omega$ to $376 \mathrm{M} \Omega$. The device delivers a peak power output of $4.5 \mathrm{~mW}$ at $198 \mathrm{M} \Omega$ load resistance and reaches $R M S$ power of $1.5 \mathrm{~mW}$.

To harvest electricity with a constant wind speed of $5 \mathrm{~m} \cdot \mathrm{s}^{-1}$, three flag materials with high electron affinity, i.e., PET, PI, and PC were systematically studied. Figure 3(c) shows the electrical output performance characteristics of WATENG with different flag materials, i.e., PI, PET and PC. The flag materials electrical performance depends on their electron affinity, surface area and fluttering frequency. The last two factors are related to its mechanical factor like high resistance to impact wind force and material rigidity. The output electrical response of these flag materials performs differently. The PI shows with a constant output voltage between $\pm 60 \mathrm{~V}$ while the PET shows between $\pm 80 \mathrm{~V}$, this level is constant over time. The high-performance PC flag material reaches a maximum output voltage between $\pm 150 \mathrm{~V}$. The voltage maximum observed indicates the increased charge $\mathrm{Q}$ and its regeneration at each cycle. A comparative short circuit currents (Isc) is shown in Figure 3(d) with the maximum Isc of $16 \mu \mathrm{A}$ in the case of PTFE: PC tribo electric pair compared to $5 \mu \mathrm{A}$ in PI and $9 \mu \mathrm{A}$ in PET flag material. The WATENGs electric output performance measured at $5 \mathrm{~m} \cdot \mathrm{s}^{-1}$ outperforms the existing reports on 
wind harvesting TENGs[24][26][32][33] which have demonstrated lower output electrical performance even at high wind velocity with larger device size.

\section{Optimum power determination}

Load matching is an important parameter to determine the effective power harvested from the system. To investigate the electrical power output of the WATENG, various external load resistances were connected to the device measured at a constant wind speed of $5 \mathrm{~m} \cdot \mathrm{s}^{-1}$. The load matching was performed using a wide-range resistance ladder configuration with load ranging from $1 \mathrm{k} \Omega$ to $376 \mathrm{M} \Omega$. The detailed experimental model is presented in the Supplementary Information S4. As shown in Figure 3(e), the WATENG reaches a peak power of $4.5 \mathrm{~mW}$ at $198 \mathrm{M} \Omega$ load resistance. Although peak power outputs provide maximum harvested power at a certain condition, it is the RMS power which is significant of the average available power for effective usage. With an RMS power of $1.5 \mathrm{~mW}$ and a peak power output of $4.5 \mathrm{~mW}$, the WATENG system outperforms the existing reports of wind energy harvesting based on triboelectric nanogenerator.

Considering the main advantages of TENG with its size, efficiency and cost effectiveness, we compare the peak power density of the reported single unit WATENG system (Figure 4(a) and Table S1) with the literature reports[24][26][32][33][34], which is 8 times higher than the existing power density of a wind based flutter-driven triboelectric nanogenerator operating in ambient conditions which work at higher wind velocity and larger device size. The proposed system is adaptable and beneficial for various storage applications for loT and sensor networks in remote locations, especially, the asynchronous non-real time applications with limited duty cycles.

\section{Applications}

LED glow

To demonstrate the performance of our proposed device as a dependable power source, we connected 40 commercial light-emitting diodes (LEDs) in series to the WATENG system as shown in Figure 4(b). Due to the relatively high fluttering frequency of the flag film in the system at a constant wind speed of $5 \mathrm{~m} \cdot \mathrm{s}^{-1}$, the generated output power was adequate to glow 40 LEDs instantaneously with a very bright illumination without any signal conditioning. The images show the series connected LEDs in OFF state and ON state in both bright and dark light conditions validating the reported WATENG 
system have many potential applications in instantaneous signaling and low maintenance energy applications.

Capacitor charging $100 \mu \mathrm{F}$

Figure 4 (c) shows the voltage profile of charging a $100 \mu \mathrm{F}$ capacitor up to $5 \mathrm{~V}$ at a wind speed of $5 \mathrm{~m} . \mathrm{s}^{-}$

1. The AC output from WATENG was converted to a DC output by a full-way rectifying bridge with equivalent circuit (Inset 4(c)). Materials such PET and PI are tested alongside PC flag film to compare the performance of its charging time. It is observed that PC flag film shows excellent result by charging capacitor from zero to $5 \mathrm{~V}$ in less than 20 seconds compared to PI and PET which consumes higher than 35 seconds validating an efficient conversion of mechanical wind energy to a stored electrical energy. Considering the rapid charging time of a $100 \mu \mathrm{F}$ in less than 20 seconds, this rapid output from the system can efficiently power low power electronic devices and wide variety of charging applications. The faster charging time can be achieved with higher wind speeds due to fact that the current and voltage output generation increases with flag fluttering frequency in accordance with the faster electron transfer between the electrodes.

\section{$1 \mathrm{mF}$ Capacitor charging}

To demonstrate the performance of our proposed TENG device for large-scale energy harvesting in real world condition, we developed a large size WATENG $(40 \times 12 \times 12 \mathrm{~cm})$ system to be mounted on a car rooftop (Movie S2 in the supplementary information) and tested it for a country side ride with varied driving speeds. This experiment provides a better vision on the possibility of WATENG in various environmental applications. The testing conditions examine various ecological and reliability challenges like varying wind speeds, humidity, pressure and mechanical force. Figure $4(d)$ demonstrates the test setup and the electrical performance of charging $1 \mathrm{mF}$ super capacitor up to 15 V. The system takes less than 12 minutes to rapidly charge the super capacitor when commuting in country side with speeds between 7-15 m.s. ${ }^{-1}$. Also, with long term device operation, no significant damage was observed in the flag material, especially in the flag tip due to high concentration of mechanical energy proving the stability and performance of PC flag in the WATENG. 


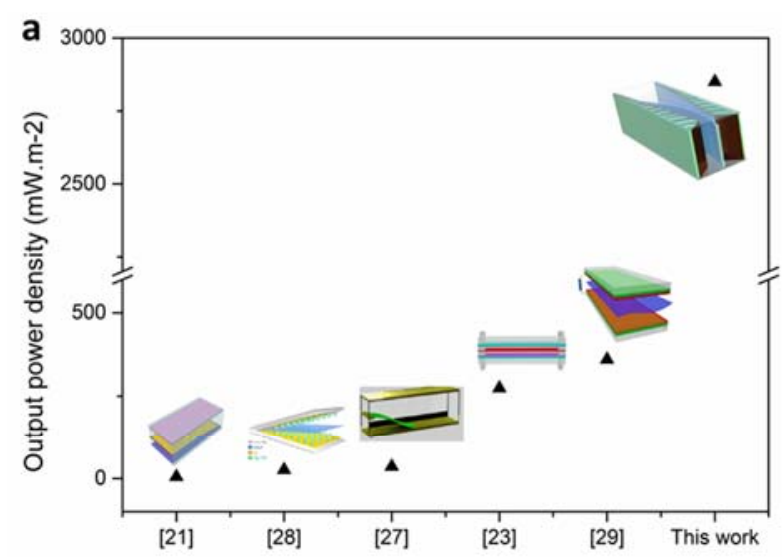

b
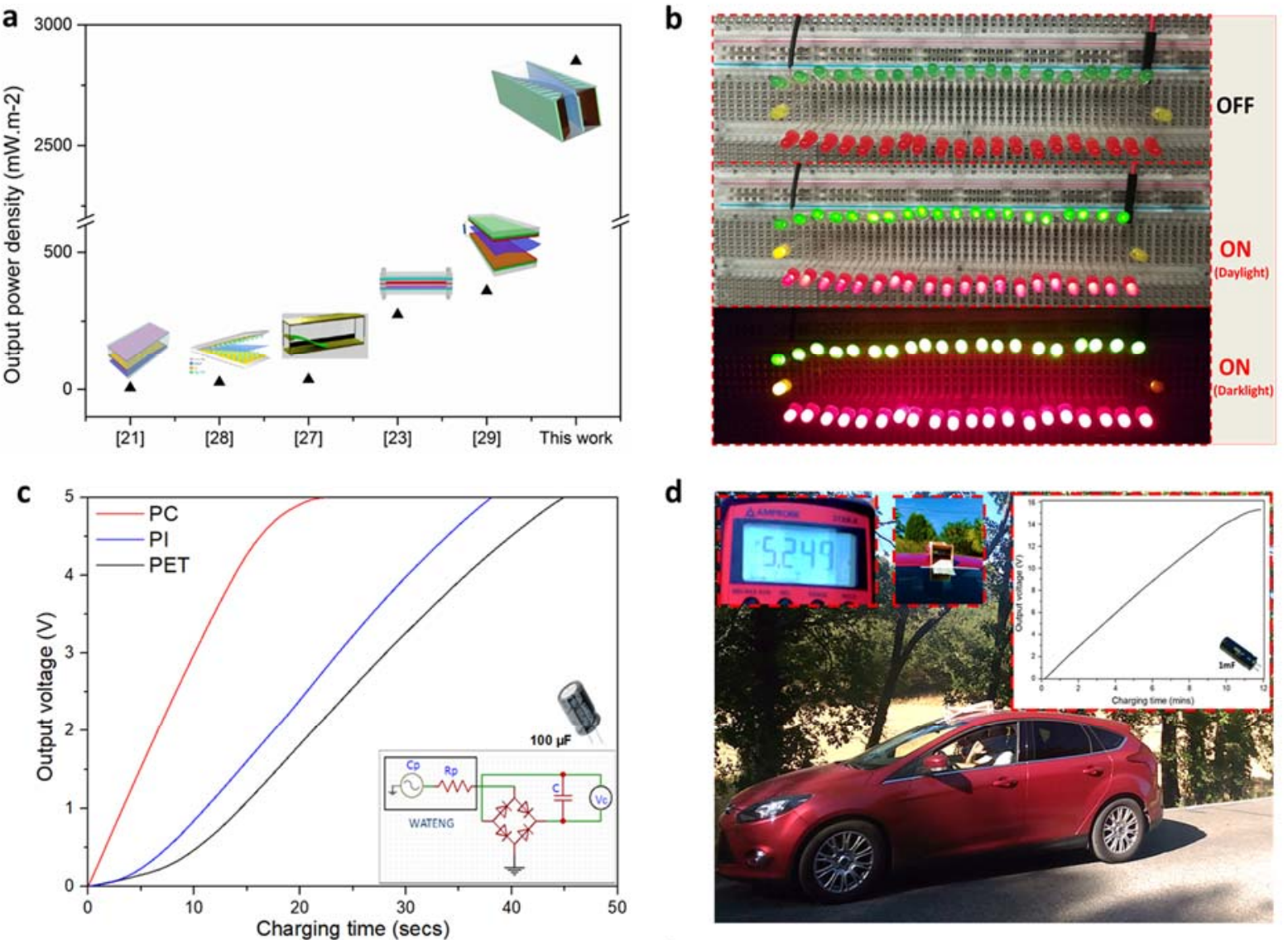

d
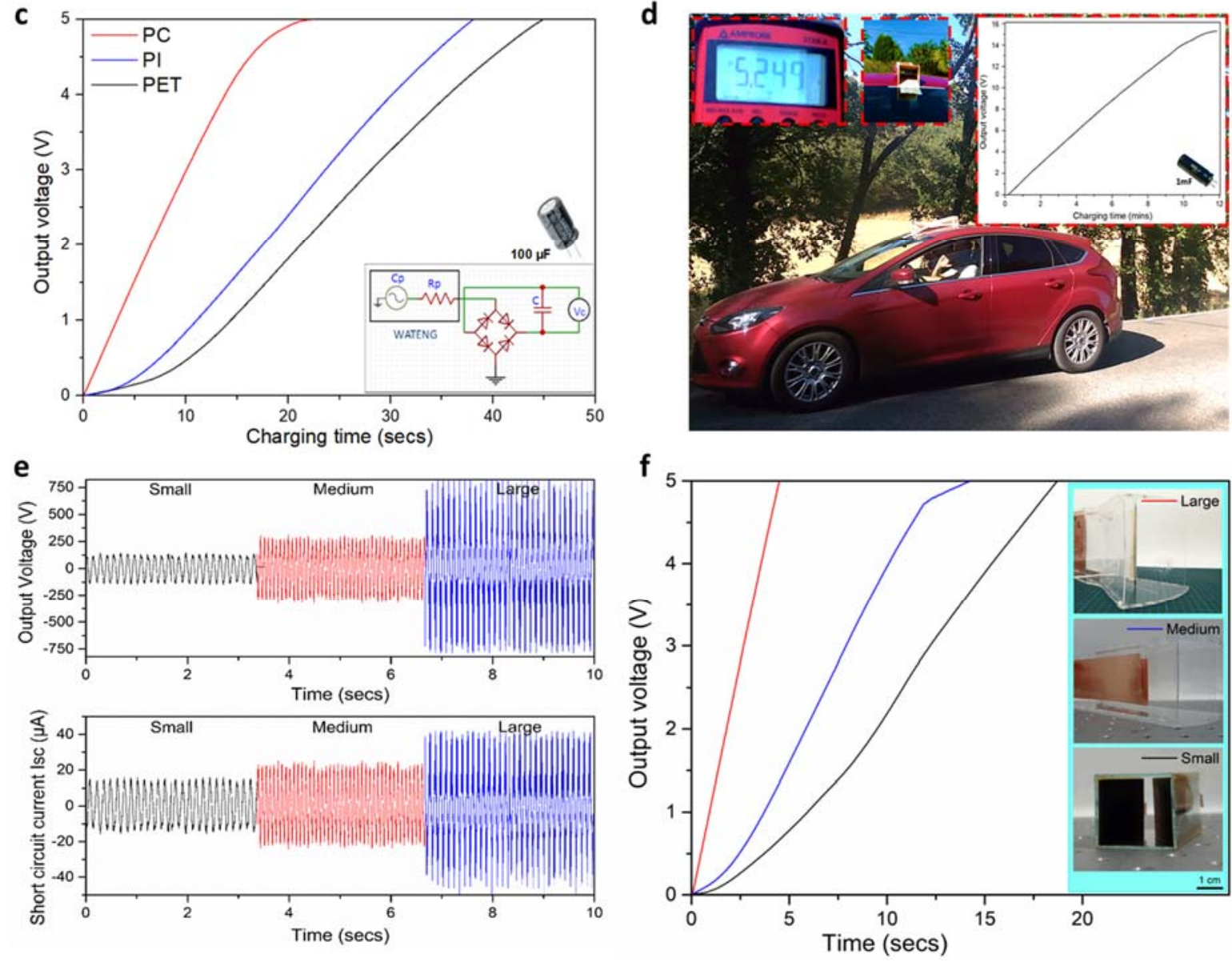

Figure 4. a) Comparison of the peak output power density of the present WATENG and previous reports based on Angle-shaped TENG[33], Wind-based TENG[34][24] and Aeroelastic flutter TENG[32][26]. b) 40 series connected commercial light-emitting diodes (LEDs) at its maximum illumination powered by WATENG system without rectification circuit, respectively in both day and dark light conditions. c) $100 \mu \mathrm{F}$ capacitor charging performance of WATENG system under different flag film materials with PTFE - CU electrode and its equivalent circuit (Inset). d) Photographs show the large-scale WATENG mounted on car roof-top to harvest ambient wind with inset showing the $1 \mathrm{mF}$ super capacitor charging up to $15 \mathrm{~V}$. The system consumes less than 12 minutes to rapidly charge a $1 \mathrm{mF}$ super capacitor. e) Measured output performance of device scaling (Large, medium and small) at a constant speed of $5 \mathrm{~m} \cdot \mathrm{s}^{-1}$. f) Comparative charging profile of $100 \mu \mathrm{F}$ up to $5 \mathrm{~V}$ for various device size.

\section{Device size comparison}

With increase in device size leading to a higher power generation due to faster charge transfer and higher contact surface area. A comparative investigation was performed on the effect of device size of the WATENG with its output electrical performances. The size of the WATENG was varied 3- 
dimensionally $(\mathrm{LxWXH})$ adapted to various charging applications. The large $(40 \times 12 \times 12 \mathrm{~cm})$ and medium $(20 \times 6 \times 6 \mathrm{~cm})$ scale WATENGs were fabricated using laser cut plexi glass that demonstrate similar device stability characteristic as the original small-scale WATENG $(7.5 \times 2.1 \times 2.1 \mathrm{~cm})$. The dependence of the voltage Vo and current Isc of the WATENG at a constant wind speed of $5 \mathrm{~m} \cdot \mathrm{s}^{-1}$ is shown in Figure. 4(e). Obviously, the highest performance of the WATENG is obtained in the largescale model $(\mathrm{Vo}=750 \mathrm{~V}$ and $I S C=40 \mu \mathrm{A})$ due to higher contact surface area and faster charge transfer rate compared to the medium-scale $(\mathrm{Vo}=270 \mathrm{~V}$ and $I s c=21 \mu \mathrm{A})$ and small-scale $(\mathrm{Vo}=150 \mathrm{~V}$ and $I s c$ $=16 \mu \mathrm{A})$ WATENG, thus making it suitable for large scale energy harvesting for autonomous applications. Furthermore, Figure 4 (f) demonstrates the charging profile of $100 \mu \mathrm{F}$ up to $5 \mathrm{~V}$ for the device size comparison. The large-scale WATENG charges rapidly in less than 5 secs while the medium and the small-scale WATENG requires 14 and 20 secs respectively. Increasing the device size not only decreases the charging time and increases the output performance but also addresses to power wide array of autonomous applications in different environmental conditions and to conceive TENGs as a primary stable power source.

\section{Conclusion}

In this paper, a wind actuated venturi triboelectric energy harvester with enhanced power output has been developed to harvest ambient mechanical energy into electricity. We have performed a systematic study between the venturi system design and the charge transfer to allow large improvements in electrical performance. The output electrical performance strongly depends on the gap spacing and the incoming wind velocity, resulting in faster charge transfer owing to faster fluttering frequency. With high impact strength and excellent triboelectric property, the $125 \mu \mathrm{m}$ polycarbonate flag film is suitable candidate for long term continuous reliable operation in complex wind environment without any significant material degradation even after 10000 oscillation cycles. The WATENG delivers an optimum RMS power of $1.5 \mathrm{~mW}$ with a maximum output power density of $2850 \mathrm{~mW} . \mathrm{m}^{-2}$ (peak power output of $4.5 \mathrm{~mW}$ ), which is much higher than the existing reports that use larger contact surface area at higher wind velocity. The generated output power was more than adequate to glow 40 LEDs instantaneously with a very bright illumination and charge a capacitor in less than 20 secs 
validating the WATENG potential in various low-power autonomous applications. Device sizing not only amplifies the output performance but also addresses to various environmental applications with an efficient charging to a storage device.

\section{References}

[1] C. Xu, C. Pan, Y. Liu, and Z. L. Wang, "Hybrid cells for simultaneously harvesting multi-type energies for self-powered micro/nanosystems," Nano Energy, vol. 1, no. 2, pp. 259-272, 2012.

[2] Y. Ramadass, "A 330nA Charger and Battery Management IC for Solar and Thermoelectric Energy Harvesting," Isscc, pp. 2011-2013, 2012.

[3] D. Purkovic, M. Honsch, and T. R. M. K. Meyer, "An Energy Efficient Communication Protocol for Low Power, Energy Harvesting Sensor Modules," IEEE Sens. J., vol. 19, no. 2, pp. 701-714, 2019.

[4] T. C. Hou, Y. Yang, H. Zhang, J. Chen, L. J. Chen, and Z. Lin Wang, "Triboelectric nanogenerator built inside shoe insole for harvesting walking energy," Nano Energy, vol. 2, no. 5, pp. 856-862, 2013.

[5] Fan, F. R., Tang, W. and Wang, Z. L. (2016), Flexible Nanogenerators for Energy Harvesting and Self-Powered Electronics. Adv. Mater., 28: 4283-4305.

[6] F. R. Fan, Z. Q. Tian, and Z. Lin Wang, "Flexible triboelectric generator," Nano Energy, vol. 1, no. 2, pp. 328-334, 2012.

[7] S. Niu and Z. L. Wang, "Theoretical systems of triboelectric nanogenerators," Nano Energy, vol. 14, pp. 161-192, 2014.

[8] D. Weisser and R. S. Garcia, "Instantaneous wind energy penetration in isolated electricity grids: Concepts and review," Renew. Energy, vol. 30, no. 8, pp. 1299-1308, 2005.

[9] J. Knight, "Breezing into town," Nature, vol. 430, no. 6995, pp. 12-13, 2004.

[10] S. H. Krishnan, "Pyroelectric-Based Solar and Wind Energy Harvesting System," ieee Trans. Sustain. energy, vol. 5, no. 1, pp. 73-81, 2014.

[11] S. Li, J. Yuan, and H. Lipson, "Ambient wind energy harvesting using cross-flow fluttering," J. Appl. Phys., vol. 109, no. 2, pp. 2-5, 2011. 
[12] C. P. and P. H. Chou, "Autonomous Energy Harvesting Platform for Multi-Supply Wireless Sensor Nodes," IEEE Sens. J., vol. 9, no. 1, pp. 168-177, 2006.

[13] M. Perez, S. Boisseau, P. Gasnier, J. Willemin, M. Geisler, and J. L. Reboud, "A cm scale electretbased electrostatic wind turbine for low-speed energy harvesting applications," Smart Mater. Struct., vol. 25, no. 4, p. 0, 2016.

[14] S. Wang, X. Wang, Z. L. Wang, and Y. Yang, "Efficient Scavenging of Solar and Wind Energies in a Smart City," ACS Nano, vol. 10, no. 6, pp. 5696-5700, 2016.

[15] J. Ma, Y. Jie, J. Bian, T. Li, X. Cao, and N. Wang, "From triboelectric nanogenerator to selfpowered smart floor: a minimalist design," Nano Energy, 2017.

[16] Kim, S. , Gupta, M. K., Lee, K. Y., Sohn, A. , Kim, T. Y., Shin, K. , Kim, D. , Kim, S. K., Lee, K. H., Shin, H. , Kim, D. and Kim, S. (2014), Transparent Flexible Graphene Triboelectric Nanogenerators. Adv. Mater., 26: 3918-3925.

[17] S. A. Nahian, R. K. Cheedarala, and K. K. Ahn, "A study of sustainable green current generated by the fluid-based triboelectric nanogenerator (FluTENG) with a comparison of contact and sliding mode," Nano Energy, vol. 38, no. April, pp. 447-456, 2017.

[18] X. Wen, Y. Su, Y. Yang, H. Zhang, and Z. L. Wang, "Applicability of triboelectric generator over a wide range of temperature," Nano Energy, vol. 4, pp. 150-156, 2014.

[19] P. A. O'Connell and G. B. McKenna, "Large deformation response of polycarbonate: Timetemperature, time-aging time, and time-strain superposition," Polym. Eng. Sci., vol. 37, no. 9, pp. 1485-1495, 1997.

[20] V. Nguyen and R. Yang, "Effect of humidity and pressure on the triboelectric nanogenerator," Nano Energy, vol. 2, no. 5, pp. 604-608, 2013.

[21] G. Zhu, B. Peng, J. Chen, Q. Jing, and Z. Lin Wang, "Triboelectric nanogenerators as a new energy technology: From fundamentals, devices, to applications," Nano Energy, vol. 14, pp. 126-138, 2014.

[22] Guang Zhu, Zong-Hong Lin, Qingshen Jing, Peng Bai, Caofeng Pan, Ya Yang, Yusheng Zhou, and Zhong Lin Wang, Nano Letters 201313 (2), 847-853. 
[23] S. Wang, X. Mu, X. Wang, A. Y. Gu, Z. L. Wang, and Y. Yang, "Elasto-Aerodynamics-Driven Triboelectric Nanogenerator for Scavenging Air-Flow Energy," ACS Nano, vol. 9, no. 10, pp. 9554-9563, 2015.

[24] B. Dudem, D. H. Kim, and J. S. Yu, "Triboelectric nanogenerators with gold-thin-film-coated conductive textile as floating electrode for scavenging wind energy," Nano Res., pp. 1-13, 2017.

[25] H. Moon, J. Chung, B. Kim, H. Yong, T. Kim, S. Lee, S. Lee, Stack/flutter-driven self-retracting triboelectric nanogenerator for portable electronicsNano Energy, 31 (2017), pp. 525-532.

[26] Q. Jiang, B. Chen, K. Zhang, and Y. Yang, “Ag Nanoparticle-Based Triboelectric Nanogenerator To Scavenge Wind Energy for a Self-Charging Power Unit," ACS Appl. Mater. Interfaces, vol. 9, no. 50, pp. 43716-43723, 2017.

[27] X. Liu, K. Zhao, and Y. Yang, "Effective polarization of ferroelectric materials by using a triboelectric nanogenerator to scavenge wind energy," Nano Energy, vol. 53, pp. 622-629, 2018.

[28] H. Yong, J. Chung, D. Choi, D. Jung, M. Cho, and S. Lee, "Highly reliable wind-rolling triboelectric nanogenerator operating in a wide wind speed range," Sci. Rep., vol. 6, no. September, pp. 111, 2016.

[29] S. Wang, L. Lin, and Z. L. Wang, "Nanoscale-triboelectric-effect enabled energy conversion for sustainable powering of portable electronics," Nano Lett., vol. 12, no. 12, pp. 6339-46, 2012.

[30] R. I. Haque, P. A. Farine, and D. Briand, "Soft triboelectric generators by use of cost-effective elastomers and simple casting process," Sensors Actuators, A Phys., vol. 271, pp. 88-95, 2018.

[31] X. Cheng, L. Miao, Y. Song, Z. Su, H. Chen, X. Chen, J. Zhang, H. Zhang, “High efficiency power management and charge boosting strategy for a triboelectric nanogenerator," Nano Energy, vol. 38, no. May, pp. 438-446, 2017.

[32] M. Xu , L. Miao, Y. Song, Z. Su, H. Chen, X. Chen, J. Zhang, H. Zhang, “An aeroelastic flutter based triboelectric nanogenerator as a self-powered active wind speed sensor in harsh environment," Extrem. Mech. Lett., vol. 15, pp. 122-129, 2017.

[33] H. Lin, M. He, Q. Jing, W. Yang, S. Wang, Y. Liu, et al, “Angle-shaped triboelectric nanogenerator 
for harvesting environmental wind energy," Nano Energy, vol. 56, pp. 269-276, 2019.

[34] Q. Jiang, B. Chen, and Y. Yang, "Wind-Driven Triboelectric Nanogenerators for Scavenging Biomechanical Energy," ACS Appl. Energy Mater., vol. 1, no. 8, pp. 4269-4276, 2018.

[35] H. Kim, S.J. Jung, Y.H. Han, H.Y. Lee, J.N. Kim, D.S. Jang, J.J. Lee, "The effect of inductively coupled plasma treatment on the surface activation of polycarbonate substrate," Thin Solid Films, 516 (2008), p. 3530.

[36] Y. Jie, Ning Wang, Xia Cao, Ying Xu, Tao Li, Xueji Zhang, and Zhong Lin Wang, "Self-Powered Triboelectric Nanosensor with Poly(tetrafluoroethylene) Nanoparticle Arrays for Dopamine Detection," ACS Nano, vol. 9, no. 8, pp. 8376-8383, 2015.

[37] C. D. Chaudhari, S. A. Waghmare, and A. Kotwal, "Numerical Analysis of Venturi Ducted Horizontal Axis Wind Turbine for Efficient Power Generation," Int. J. Mech. Eng. Comput. Appl., vol. 1, no. 5, pp. 90-93, 2013.

[38] M. L. Jackson and W. Collins, "Scale-up of a Venturi Aerator," Ind. Eng. Chem. Process Des. Dev., vol. 3, no. 4, pp. 386-393, Oct. 1964.

[39] N. E. Nasr, G. G.; Connor, Natural Gas Engineering and Safety Challenges: Downstream Process, Analysis, Utilization and Safety. Springer US, 2014.

[40] C. G. Justus and Amir Mikhail School, "HEIGHT VARIATION OF WIND SPEED AND WIND DISTRIBUTIONS STATISTICS," Geophys. Res. Lett., vol. 3, no. 5, 1976.

[41] Daniel Kinseth Reitan, "Accurate Determination of the Capacitance of Rectangular Parallel-Plate Capacitors," J. Appl. Phys., vol. 30, no. 2, pp. 172-176, 1959.

[42] C. F. Gallo and W. L. Lama, "Some charge exchange phenomena explained by a classical model of the work function," J. Electrostat., vol. 2, no. 2, pp. 145-150, Jun. 1976.

[43] J. X. Zhang, "Analysis on the effect of venturi tube structural parameters on fluid flow," AIP Adv., vol. 7, no. 6, 2017.

[44] Z. L. Wang, L. Lin, J. Chen, S. Niu, and Y. Zi, Triboelectric Nanogenerators-Freestanding Triboelectric-Layer Mode. 2016.

[45] Z. L. Wang, "Triboelectric nanogenerators as new energy technology and self-powered sensors 
- Principles, problems and perspectives," R. Soc. Chem., vol. 7, no. 11, pp. 9533-9557, 2014.

\section{Acknowledgement}

This research was supported under the AMPEERS-2 project by the theme "Networks and energy storage"'. The authors thank to the facility support of the Institut des Sciences du Mouvement - Equipe Biorobotique, Marseille.

\section{Author Contributions}

A.R., C.C. and S.B. designed and fabricated the structures. A.R. and M.R. characterized the devices. A.R., S.B. and M.R. analyzed the experimental data and prepared the manuscript. J.S. provided support related to the high-speed camera on understanding the wind flag behavior.

\section{Appendix A. Supplementary information}

S1: Detailed working mechanism of WATENG.

S2: Sequential images of contact-separation behavior. Images were captured using a high-speed camera with a constant wind flow velocity of $5 \mathrm{~m} \cdot \mathrm{s}^{-1}$ at a time interval of $1.317 \mathrm{~s}$.

S3: Derivations of the formulae

Table S1: Comparison of WATENG output performance with previous reports.

\section{Movies}

Movie S1: Flag fluttering oscillations of captured using a high-speed camera (Phantom Miro M110) at a frame rate of 1600 frames per second at full $1280 \times 800$-pixel resolution is employed.

Movie S2: Real world application employing WATENG for large scale energy harvesting mounted on a moving vehicle.

\section{Highlights}

- A compact and high performance wind actuated venturi triboelectric energy harvester is demonstrated and shows enhanced output power density in comparison to previous reports.

- The study on relation between the venturi throat gap spacing and the charge transfer leading to the conceptualization of an optimized device at low wind speeds.

- A Polycarbonate (PC) flag film is employed to overcome issues related to long term reliable operation in complex wind environment. The material performed without any significant material degradation even after 10000 oscillation cycles 
- Device sizing not only amplifies the output performance but also addresses to various environmental applications with an efficient charging to a storage device.

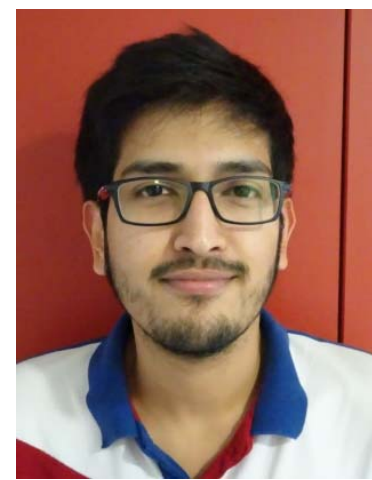

Aravind Narain Ravichandran is currently a PhD student in the Flexible Electronics Department at the Campus Georges Charpak Provence of Mines Saint Etienne working on wearables based on triboelectric nanogenerators. He obtained his Master of Science from ESIEE Paris in 2015 focusing on MEMS and micro-nano technologies and worked as a research engineer in Singapore, where he developed gas sensors based on acoustic and electromagnetic transductions. His research interests include energy harvesters, microfabrication technologies and self-powered sensors.

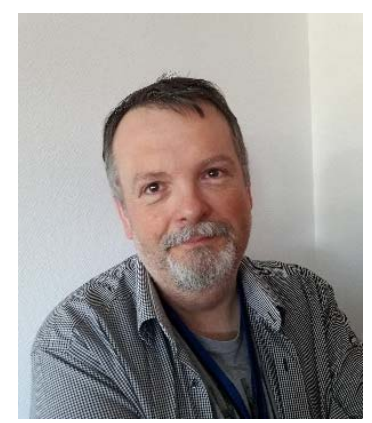

Cyril Calmes completed his studies at University Montpellier II in material sciences and received his PhD at the Institute of Fundamental Electronics at the University of Paris XI - ORSAY (France). He is currently working as a research engineer at the Flexible Electronics Department at the Campus Georges Charpak Provence of Mines Saint Etienne.

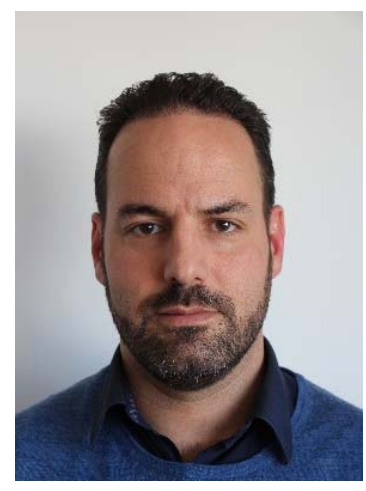

Julien R Serres is a lecturer in Biorobotics Group at the Institute of Movement Sciences, CNRS, Aix Marseille University, Marseille, France. He obtained his MSc degree in Electronics, Electrotechnics, and Automatic Control engineering from Paris XI University and the ENS Cachan, Orsay, France, in 2003. He earned his Ph.D. degree at the University of Montpellier II in July 2008. His current research interests include biomimecry, biorobotics, bioinspired mechanical systems, bio-inspired visual sensors, and the development of bio-inspired autopilot aimed at equipping autonomous robots.

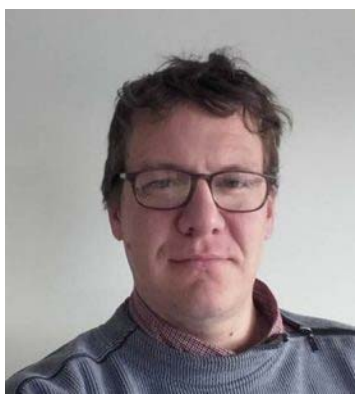

Marc Ramuz received his PhD in 2010 from the Centre Suisse d'Electronique et de Microtechnique (CSEM) in Zürich. Then he joined Zhenan Bao group in Stanford for two years postdoctoral. In 2012, he undertook a postdoctoral fellowship in the Bioelectronics department of the School of Mines Saint 
Etienne under the supervision of Róisín Owens. He is currently an associate professor in Flexible Electronics Department at the Campus Georges Charpak Provence of Mines Saint Etienne. He is coauthor of more than 30 peer-reviewed scientific publications, including 10 as first author. His research interests are related to multi-stack sensors for artificial skin, soft/stretchable electronic and investigation of nanomaterials for energy conversion and storage, including nanogenerators.

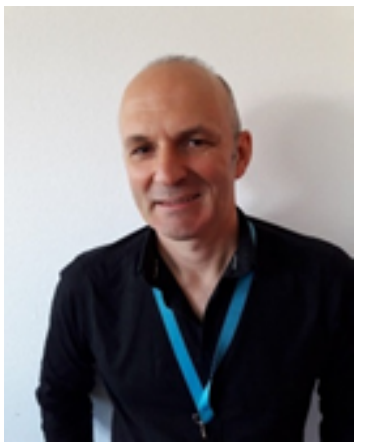

Sylvain Blayac was born in 1972. He received the M.S. degree in electronics from the University of Montpellier, Montpellier, France in 1997, and the Ph.D. degree in electronics in 2001. He then joined Alcatel, Paris, France, as a Device Physical and Electrical Modeling Engineer for high-speed fiber-optic communication circuits. He joined the Provence Microelectronics Center, Ecole de Mines de Saint-Étienne, Gardanne, France, in 2003, where he became a Teacher of semiconductor devices physics and conducted research on embedded stress sensors. His current research interests include flexible sensors and energy harvesting devices. Professor Blayac authored and co-authored more than 50 communications in refereed international journals and conferences and holds 7 patents. 


\section{Supplementary information}

\section{Compact and High Performance Wind actuated venturi triboelectric energy harvester}

Aravind Narain Ravichandran ${ }^{a}$, Cyril Calmes ${ }^{a}$, Julien R Serres ${ }^{b}$, Marc Ramuz ${ }^{a}$, Sylvain Blayac ${ }^{a}$

${ }^{a}$ Mines Saint-Etienne, Center of Microelectronics in Provence, Department of Flexible Electronics, France

${ }^{\mathrm{b}}$ Aix Marseille Univ, CNRS, ISM, Marseille, France

\section{S1. Detailed working mechanism of WATENG}
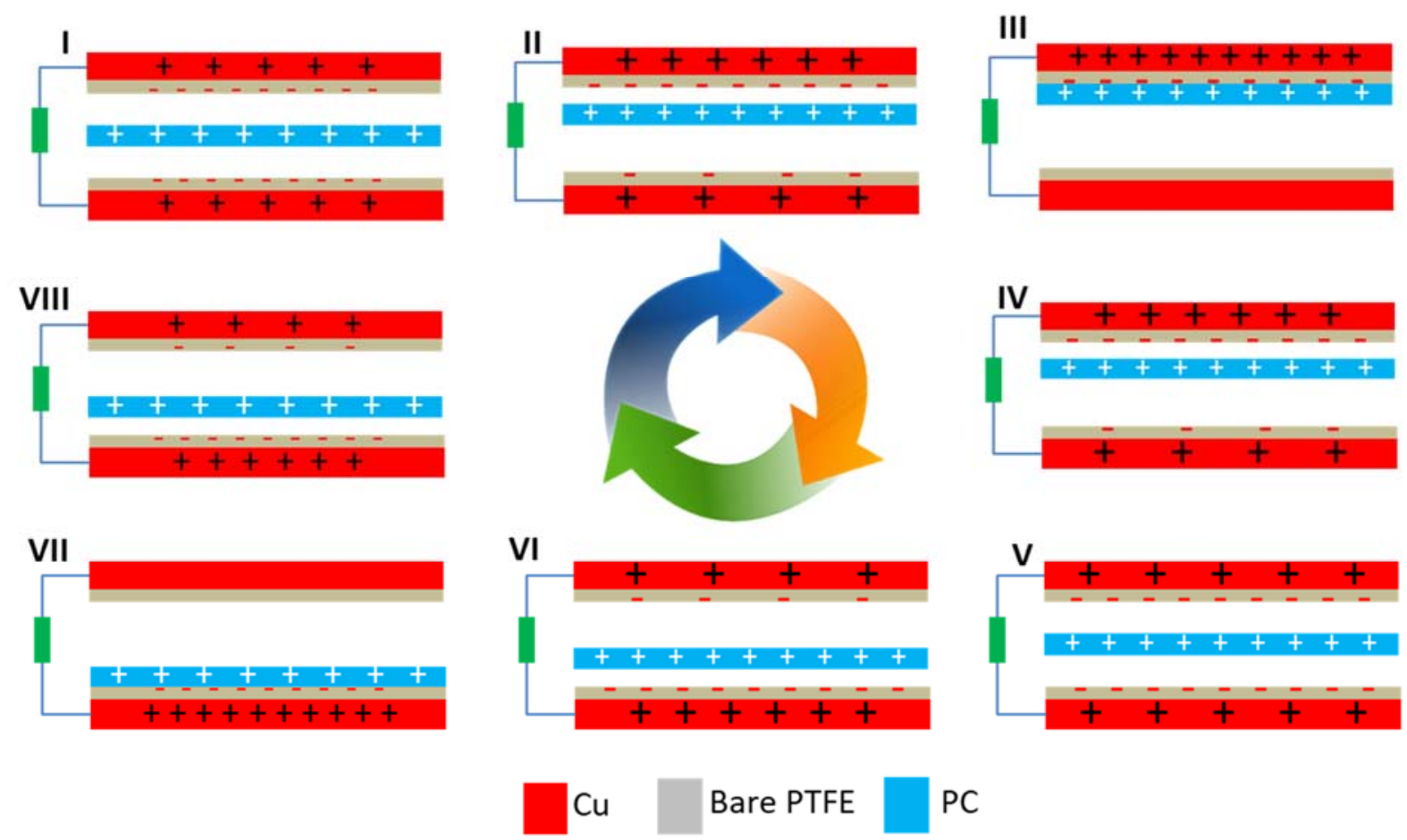

PC

S1. The working principle of the WATENG. (I) There exists no electric potential difference between the top and bottom Cu electrodes. (II) As the wind enters the system, the PC flag displaces from its initial position towards the top electrode due to the pressure depression created in the venturi system design. (III) When the flag contacts the top PTFE film the negative charges would be created due to triboelectrification, leaving the PC positively charged. The charges on the Cu electrodes flows through the external circuit due to the electrostatic induction of the PC flag. (V-VII) The flag displaces towards the bottom electrode material driving the electron flow from bottom copper layer to the top electrode until the flag contacts the top electrode material transferring the charges to the PTFE - Cu electrode due to triboelectrification process giving rise to a potential difference between the top and bottom electrodes. A continuous alternating current is produced due to the periodic charge transfer flow between the top and the bottom electrode material. 
S2. Sequential fluttering behavior images captured using a high-speed camera with a constant wind flow velocity of $5 \mathrm{~m} \cdot \mathrm{s}^{-1}$ at a time interval of $1.317 \mathrm{~s}$.
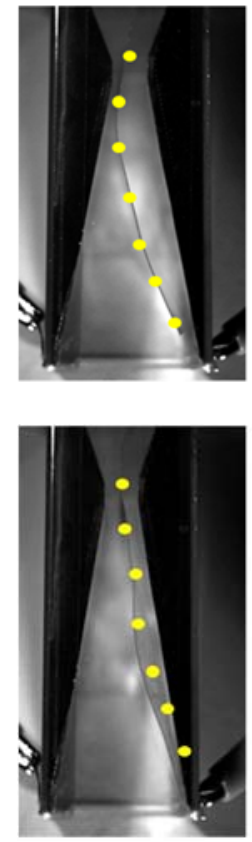
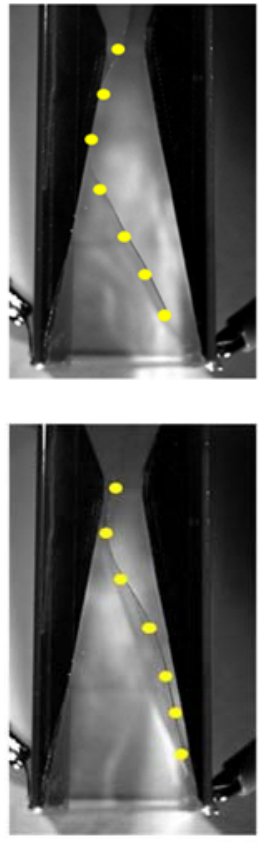
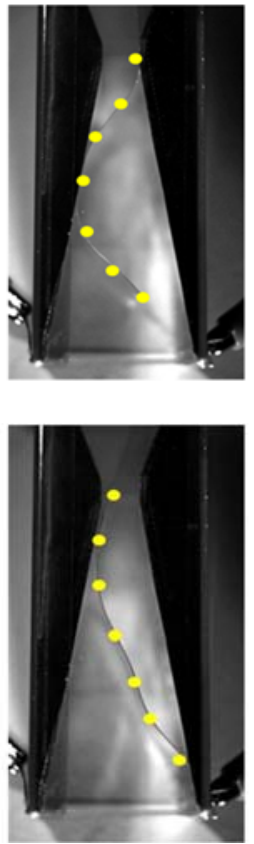
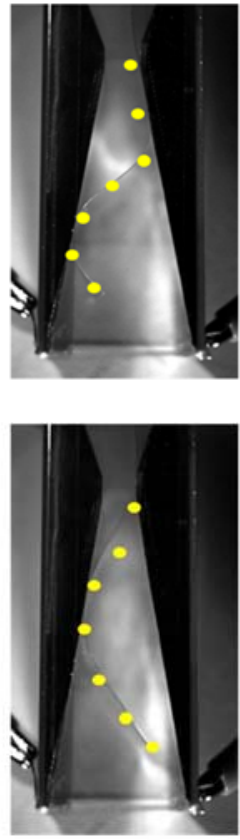
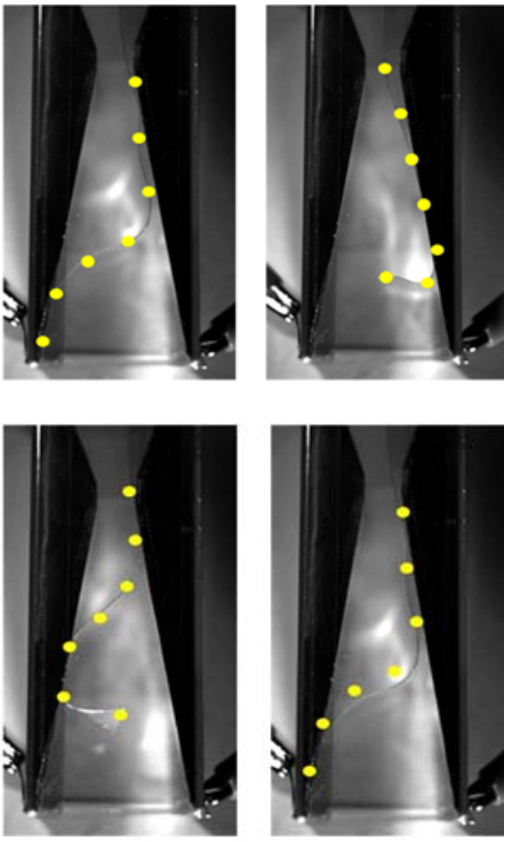

\section{S3: Derivation of the formulae}

A simplified device configuration of the wind actuated venturi triboelectric energy harvester is presented in

Figure S1. The amount of electric charge Qe created on the moving flag remains a constant and is linearly related to the change in electric potential $\mathrm{V}$ at a certain wind velocity and the capacitance $\mathrm{C}$. This relation can be seen as

$$
Q_{e}=C . V
$$

The capacitance $C_{\text {total }}$ between the electrodes depends with a gap distance $2 \mathrm{w}$ and a contact surface area of the electrodes $A$.

$$
C_{\text {total }}=\frac{\in A}{2 w}
$$

In open circuit conditions, the electrodes are not shorted resulting in an electrode potential between the electrodes known as the open circuit voltage $\left(\mathrm{V}_{\mathrm{oc}}\right)$.

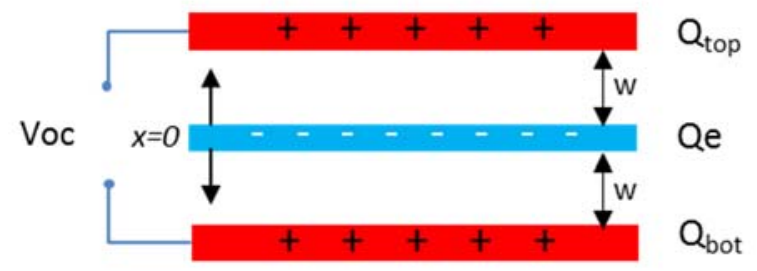

a. Open circuit condition

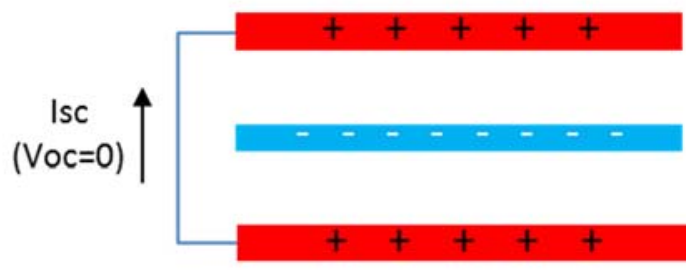

b. Short circuit condition

Figure 1. Schematic showing the open and short circuit conditions 
As shown in Fig. 1(a), with equal charges present on the electrodes (Qtop and Q bottom) and the flag, the charge $Q$ e at the initial position $(x=0)$ is given by

$$
\begin{aligned}
& \left|Q_{e}\right|=Q_{\text {top }}+Q_{\text {bottom }} \\
& Q_{\text {bottom }}=\left|Q_{e}\right|-Q_{\text {top }}
\end{aligned}
$$

The total output voltage $V_{\text {total }}$ across the electrodes with a fixed capacitance $\left(C_{\text {top }}\right.$ and $C_{\text {bottom }}$ ) and a displacement $\mathrm{x}$ is given by

$$
\begin{gathered}
V_{\text {total }}=V_{\text {top }}+V_{\text {bottom }} \\
V_{\text {total }}=\frac{Q_{\text {top }}}{C_{\text {top }}}-\frac{Q_{\text {bottom }}}{C_{\text {bottom }}}=\frac{Q_{\text {top }}}{C_{\text {top }}}-\frac{\left(\left|Q_{e}\right|-Q_{\text {top }}\right)}{C_{\text {bottom }}} \\
V_{\text {total }}=Q_{\text {top }}\left(\frac{(w-x)}{\in A}+\frac{(w+x)}{\in A}\right)-\frac{\left|Q_{e}\right|(w+x)}{\in A} \\
V_{\text {total }}=Q_{\text {top }} \frac{2 w}{\in A}-\frac{\left|Q_{e}\right|(w+x)}{\in A}
\end{gathered}
$$

At each half cycles when flag position $x=+w$ and $x=-w$, we get from (8),

$$
\begin{gathered}
V_{\text {total }}=Q_{\text {top }} \frac{2 w}{\in A}-\frac{\left|Q_{e}\right|(w+x)}{\in A} \\
V_{\text {total }}=Q_{\text {top }} \frac{2 w}{\in A}
\end{gathered}
$$

For a full cycle, from (9) and (10), the amplitude of voltage $V_{\text {peak-to-peak }}$ is deduced to

$$
V_{\text {peak-to-peak }}=\frac{\left|Q_{e}\right|}{\in A} \cdot 2 w
$$

When the electrodes are shorted (Fig. $1(b), V_{\text {total }}=0$. The charges flow freely between the two electrodes.

$$
\begin{aligned}
& 0=Q_{\text {top }} \frac{2 w}{\in A}-\frac{\left|Q_{e}\right|(w+x)}{\in A} \\
& Q_{\text {top }}=\frac{\left|Q_{e}\right|(w+x)}{\in A} \cdot C_{\text {total }}
\end{aligned}
$$

The short-circuit current $\left(\mathrm{I}_{\mathrm{sc}}\right)$ is expressed as

$$
\begin{gathered}
I_{s c}=\frac{d Q_{t o p}}{d t}=\frac{d}{d t}\left(\left|Q_{e}\right| \cdot\left(\frac{1}{2}+\frac{x}{2 w}\right)\right) \\
I S c=\left|Q_{e}\right| \cdot \frac{v}{2 w}
\end{gathered}
$$

The wind velocity $v$ is the rate of change of displacement, $v=d x / d t$. The flag displacement between the two electrodes is arbitrated by the fluttering frequency which inherently depends on the input wind velocity. Therefore, the frequency $f$ as a function of wind velocity and gap distance can be expressed as 


$$
f=\frac{v}{w}
$$

The rate of transfer of charges primarily depends on the wind velocity and the output short current Isc and is given by

$$
I_{s c}=\left|Q_{e}\right| \cdot \frac{f}{2}
$$

\section{S4: Measurement of open-circuit voltage (Voc) using Resistance ladder configuration}

In order to measure the power harvested from the wind actuated venturi triboelectric energy harvester, we device a resistance ladder configuration. A resistor ladder $\mathrm{nR}$ is an electrical circuit made from repeating units of resistors.
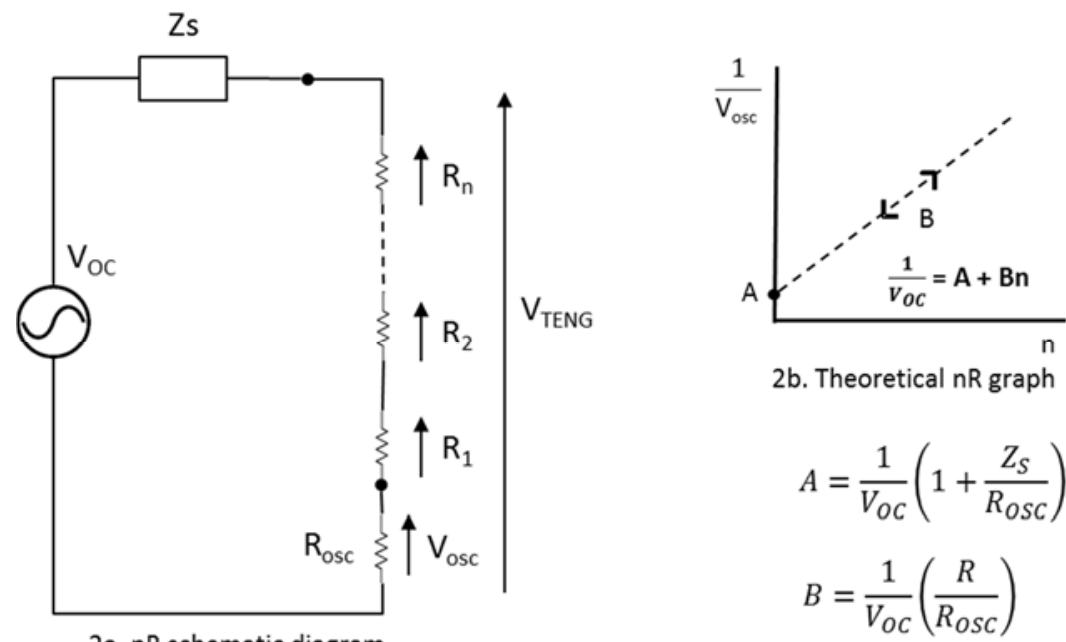

$$
\begin{aligned}
& A=\frac{1}{V_{O C}}\left(1+\frac{Z_{S}}{R_{O S C}}\right) \\
& B=\frac{1}{V_{O C}}\left(\frac{R}{R_{O S C}}\right)
\end{aligned}
$$

From Fig. 2a, the output voltage $V_{\text {osc }}$ from the oscilloscope is expressed as

$$
V_{O S C}=V_{T E N G}\left(\frac{R_{O S C}}{R_{O S C}+n R}\right)
$$

The voltage $V_{\text {TENG }}$ across the $n R$ and the $V_{\text {osc }}$ is given by

$$
V_{T E N G}=V_{O S C}\left(1+\frac{n R}{R_{O S C}}\right)
$$

The average voltage $V_{\text {RMS }}$ of a periodic waveform (sine wave or triangular waveform) is given as the average instantaneous values along time axis with a period of wave $\tau$. The RMS value of any time varying waveform is defined as

$$
V_{R M S}=\sqrt{\frac{1}{\tau} \int_{0}^{\tau} V^{2}(t) \cdot d t}
$$

The average output voltage with a maximum voltage $V_{\max }$ of a sinusoidal waveform over one full-cycle is given by 


$$
V_{R M S}=\frac{V_{\max }}{\sqrt{2}}
$$

The output waveform of the WATENG resembles a triangular output signal. Consider a full cycle triangular voltage waveform that is symmetrical about $\mathrm{V}=0$ and a period of wave $\tau$. Let the maximum voltage be $+\mathrm{Vmax}$ and minimum voltage $-V m a x$. Integrating from $(0-\tau / 4)$ to calculate the RMS output.

$$
V(t)=\frac{4 V_{\max }}{\tau} \cdot t
$$

valid between $\mathrm{t}=0$ and $\mathrm{t}=\mathrm{\tau} / 4$. From (20) and (22), we get

$$
V_{R M S}=\sqrt{\frac{4}{\tau}\left(\frac{4 V_{\max }}{\tau}\right)^{2} \cdot \int_{0}^{\frac{\tau}{4}} t^{2} d t}
$$

The average output voltage $V_{\text {RMS }}$ from (23) can be deduced as

$$
V_{R M S}=\frac{V_{\max }}{\sqrt{3}}
$$

From (19) and (24), the output power $P_{\text {out }}$ across $V_{\text {TENG }}$ with resistance load $R_{\text {load }}\left(R_{\text {load }}=R_{\text {osc }}+n R\right)$ is given by

$$
P_{\text {Out }}=\frac{V_{T E N G}{ }^{2}}{3 \cdot R_{\text {load }}}
$$


Table S1: Comparison of WATENG output performance with previous reports. The peak output power density of the present WATENG and previous reports based on Angle-shaped TENG, Wind based TENGs and Aeroelastic flutter TENG[1][2][3][4][5]

Device architecture Size [cm2] Wind speed Vout (V) Current (Isc) Power density Ref.

\begin{tabular}{|c|c|c|c|c|c|c|}
\hline $\begin{array}{l}\text { Wind-based TENGs } \\
\text { (W-TENGs) }\end{array}$ & $7.5 \times 2.5$ & $6.8 \mathrm{~m} \cdot \mathrm{s}^{-1}$ & $49 \mathrm{~V}$ & $5 \mu \mathrm{A}$ & $5.12 \mathrm{~mW} \cdot \mathrm{m}^{-2}$ & [1] \\
\hline $\begin{array}{l}\text { Angle-shaped TENG } \\
\text { (AS-TENG) }\end{array}$ & $5.5 \times 2.4$ & $10 \mathrm{~m} \cdot \mathrm{s}^{-1}$ & $64 \mathrm{~V}$ & $2.5 \mu \mathrm{A}$ & $26 \mathrm{~mW} \cdot \mathrm{m}^{-2}$ & [2] \\
\hline $\begin{array}{l}\text { Aeroelastic flutter } \\
\text { based triboelectric } \\
\text { nanogenerator (AF- } \\
\text { TENG) }\end{array}$ & $2 \times 12$ & $10 \mathrm{~m} \cdot \mathrm{s}^{-1}$ & $20 \mathrm{~V}$ & $2 \mu \mathrm{A}$ & $36 \mathrm{~mW} \cdot \mathrm{m}^{-2}$ & [3] \\
\hline $\begin{array}{l}\text { Ag nanoparticles-based } \\
\text { TENG }\end{array}$ & $5 \times 1$ & $20 m \cdot s^{-1}$ & $200 \mathrm{~V}$ & $20 \mu \mathrm{A}$ & $274 \mathrm{~mW} \cdot \mathrm{m}^{-2}$ & [4] \\
\hline $\begin{array}{l}\text { Ag NWs-based wind- } \\
\text { driven TENG }\end{array}$ & $5 \times 1$ & $20 \mathrm{~m} \cdot \mathrm{s}^{-1}$ & $150 \mathrm{~V}$ & $7.5 \mu \mathrm{A}$ & $360 \mathrm{~mW} \cdot \mathrm{m}^{-2}$ & [5] \\
\hline $\begin{array}{l}\text { Wind actuated venturi } \\
\text { TENG (This work) }\end{array}$ & $6.5 \times 2.1$ & $5 \mathrm{~m} \cdot \mathrm{s}^{-1}$ & $150 \mathrm{~V}$ & $16 \mu \mathrm{A}$ & $2850 \mathrm{~mW} \cdot \mathrm{m}^{-2}$ & \\
\hline
\end{tabular}

\section{References}

[1] B. Dudem, D. H. Kim, and J. S. Yu, "Triboelectric nanogenerators with gold-thin-film-coated conductive textile as floating electrode for scavenging wind energy," Nano Res., pp. 1-13, 2017.

[2] H. Lin et al., "Angle-shaped triboelectric nanogenerator for harvesting environmental wind energy," Nano Energy, vol. 56, pp. 269-276, 2019.

[3] M. Xu et al., "An aeroelastic flutter based triboelectric nanogenerator as a self-powered active wind speed sensor in harsh environment," Extrem. Mech. Lett., vol. 15, pp. 122-129, 2017.

[4] Q. Jiang, B. Chen, K. Zhang, and Y. Yang, "Ag Nanoparticle-Based Triboelectric Nanogenerator To Scavenge Wind Energy for a Self-Charging Power Unit," ACS Appl. Mater. Interfaces, vol. 9, no. 50, pp. 43716-43723, 2017.

[5] Q. Jiang, B. Chen, and Y. Yang, "Wind-Driven Triboelectric Nanogenerators for Scavenging Biomechanical Energy," ACS Appl. Energy Mater., vol. 1, no. 8, pp. 4269-4276, 2018. 